\title{
The Experimental Research on Independent Starting and Autonomous Operation of HDTB Considered as a Basic Block of AES Based on Supercritical Hydrothermal Destruction
}

\author{
A.D. Vedenin, V.S. Grigoryev, Ya.P. Lobatchevskiy, A.I. Nikolaev, \\ G.S. Savelyev and A.V. Strelets
}

\begin{abstract}
This article deals with an independent starting system (ISS) of the hydrothermal destruction test bed (HDTB) as a part of the layout of the autonomous energy system (AES) based on environmentally friendly technology of supercritical hydrothermal destruction (SCHD) of organic waste and fuels to supply electric and heat energy to small-scale distributed energy facilities. Independent starting system and HDTB tests which may be considered as AES basic block while using liquefied hydrocarbon gas (LHG) as a fuel for AGP-30 gas-piston power plant (GPPP) included into ISS have been described in the paper. Formation of combustible gas as a result of hydrothermal destruction of aqueous mixtures of organic waste and fuels has been shown experimentally. The produced combustible gas may have rather high net calorific value (NCV), which could define its suitability to be used to provide autonomous operation of HDTB.
\end{abstract}

\footnotetext{
A.D. Vedenin · V.S. Grigoryev · Ya.P. Lobatchevskiy ·

G.S. Savelyev · A.V. Strelets $(\bowtie)$

Scientific Research Institute of Agricultural Mechanization (FGBNU VIM),

Moscow, Russia

e-mail: streletsav@ya.ru
}

A.D. Vedenin

e-mail: advedenin@yandex.ru

V.S. Grigoryev

e-mail: 1117731@mail.ru

Ya.P. Lobatchevskiy

e-mail: Lobachevsky@ya.ru

G.S. Savelyev

e-mail: ovlov2012@yandex.ru

\author{
A.I. Nikolaev \\ Dmitry Mendeleev University of Chemical Technology of Russia, Moscow, Russia \\ e-mail: aeshilus@gmail.com \\ (C) The Author(s) 2018


Keywords Autonomous energy - Renewable energy sources - Supercritical technologies - Hydrothermal destruction - Gas-Piston power plant

\section{Introduction}

The development of renewable energy sources (RES) may remain a key task for Russian power-engineering in respect that around $15 \%$ of population is considered to consume energy from small-scale distributed energy facilities [1] while inhabiting two-thirds of the Russian territory. The importance of the decentralized energy development designated under the Energy Strategy of Russia for the Period up to 2035 Decree and aimed at "maximizing the cost effective use of domestic fuel and energy resources, developing cost effective decentralized and individual heat supply systems..." with regard to the facilities of housing and community amenities (HCA) as well as of agricultural and industrial production may be increasing due to the continual widening of an environmental damage scope caused by their organic wastes. It stands to reason that a considerable thought has been given to environmental safety by the society and the authorities, so the 2017 year is announced as a Year of Environment in Russia by the President of the Russia Federation (RF). The official plan of events for the Year of Environment approved by the RF government includes a special section dealing with waste disposal problems.

Despite the remarkable technological progress in developing power plants based on RES, the investigations on the development of AES to produce energy during organic waste and low grade fuels recycling may be at the stage of the experimental data accumulation as well as evaluation of physicochemical properties and the elucidation of the main trends during the process of destruction along with the facility design development [2].

Thus, the advantages of using power plants based on SCHD could be rather a significant factor for industries involving the production of organic waste and fuels (e.g., lignin-containing waste, animal and vegetable waste, wood waste) in hard-to-reach and remote areas, being a feedstock for them.

The technology of supercritical hydrothermal destruction or, as it is also called, supercritical water oxidation (SCWO) is based on the use of supercritical water (temperature and pressure are higher than $374.15^{\circ} \mathrm{C}$ and $220.64 \mathrm{bar}$, respectively). Under such conditions, not only may water obtain properties different from those of liquid and vapor phases such as high density, low viscosity, and substantial diffusion, but also a change in its nature (from polar to almost nonpolar substance) may occur. This enables water to dissolve various organic matters including those forming solid coal-like matters and tars. Minimum demands on feedstock humidity may be imposed by conducting the reaction in an aqueous medium. A number of investigations [3] on supercritical water gasification (SCWG) of various types of biomass and methods for realization of biomass are known, though the application problems of the product in terms of ensuring autonomous operation of the energy system have not yet been considered. 
Being a variety of gasification of conventional fuels and biomass of different origin [4], hydrothermal pyrolysis may be used solely to produce gas fuel having high content of hydrogen, methane and other high-energy ingredients. As a result of various investigations on hydrothermal gasification, almost any formation of carbonaceous matters may be observed. External heat supply may be required while conducting hydrothermal pyrolysis as the pyrolysis process is endothermic, which may correspond to HDTB allothermal regime.

At the same time, hydrothermal oxidation may imply addition of the oxidizer to supercritical water and allow obtaining the complete conversion of organic matter to water and carbon dioxide [5-7]. Formation of incombustible gas-vapor mixture may occur at rather appreciable heat evolution, which may ensure the conducting of the process without constant external heat supply and correspond to HDTB autothermal regime [8]. Thus, HDTB operation may open up alternative possibilities for the energy production due to the use of gas-piston power plant (GPPP) in allothermal regime, and it would be advisable to use steam microturbine in autothermal regime.

Previous investigations as well as an accumulated experience have shown the capability of the power plants based on SCHD to recycle a wide range of organic waste including pesticides and other persistent organic pollutants (POPs) [7, 9]. However, to provide usability of the SCHD technology at various power plants, the mobility as well as the autonomy of the processing plants. The presence of power supply source independent of external network may be one of the methods to provide the autonomy of energy systems, for example, in terms of energy supply. Thus, a need has been recognized for the development of HDTB independent starting and autonomous operation. An experimental research on the ISS including GPPP has been carried out in the context of the investigation, while liquefied hydrocarbon gas (LHG) has been used as a fuel.

\section{Methods}

The independent starting system of HDTB (Fig. 1) based on AGP-30 gas-piston power plant (rated capacity of $30 \mathrm{~kW}$ and fuel consumption of $15 \mathrm{~nm}^{3} / \mathrm{h}$ ) equipped with a control system may include the following:

- LHG gas cylinders (E);

- accumulator battery (ACB);

- gas filter with a shut-off valve (FSV);

- gas reducer-evaporator (RE);

- gas pressure and flow sensor (GFS);

- shut-off needle valve block (VB);

- electric water pump (WP);

- electric direct-flow water heater (DWH). 


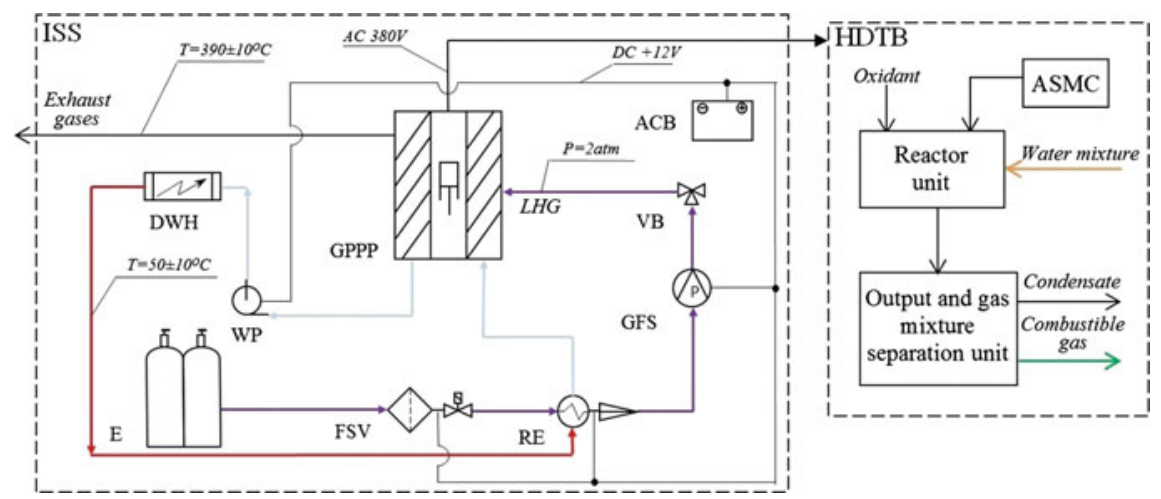

Fig. 1 A schematic of HDTB independent starting system

The use of LHG (propane/butane mix [10]) as a fuel for AGP-30 may be determined by its broad accessibility and relative cheapness as well as the possibility to be transported and stored in household gas cylinders.

The experimental research has been carried out in compliance with test agenda and procedure developed within the context of the second stage of the applied research and exploratory development.

The principle of ISS operation may be the following. To provide constant gas-phase fuel feeding to the gas fuel system of GPPP, the water heater should be brought into operation before starting GPPP. Circulation of refrigerating fluid through the water heater could be obtained by GPPP motor pump powered in turn by the accumulator battery. On opening the shut-off valve, gas after additional cleaning in the filter may flow from the cylinder to the reducer-evaporator where it may transform into gas phase with the required pressure. Then gas may flow through the gas pressure and flow sensor and the valve block and enter the input of the AGP-30 gas fuel system (Fig. 2).

The operator should perform starting algorithm procedures stipulated by the instruction, and gas may be fed from the cylinder as well as the power plant may be started in a manual mode. After starting, the engine may automatically turn into an operative mode with unvarying operating parameters of the power plant, consequently through low idle and nominal speed condition. After GPPP reaches full operation, HDTB could be connected to it for experimental verification of the possibility of independent starting and autonomous operation. The reactor could be heated up within 1 hour while water could be fed to reach the point of operating parameters of $\mathrm{T}=450 \div 550{ }^{\circ} \mathrm{C}, \mathrm{P}=23 \mathrm{MPa}$ due to the energy produced by the power plant.

To conduct SCHD reaction, $10 \%$ (by mass) aqueous mixtures of organic waste and fuels divided into $3 \mathrm{~kg}$ portions have been prepared at the developed process equipment for aqueous mixture preparation which may be the part of AES: 1 is rape oil emulsion; 2 is crushed buckwheat hull suspension; 3 is whey solution. The aqueous mixtures have been fed to the reactor which may be a key element of the 


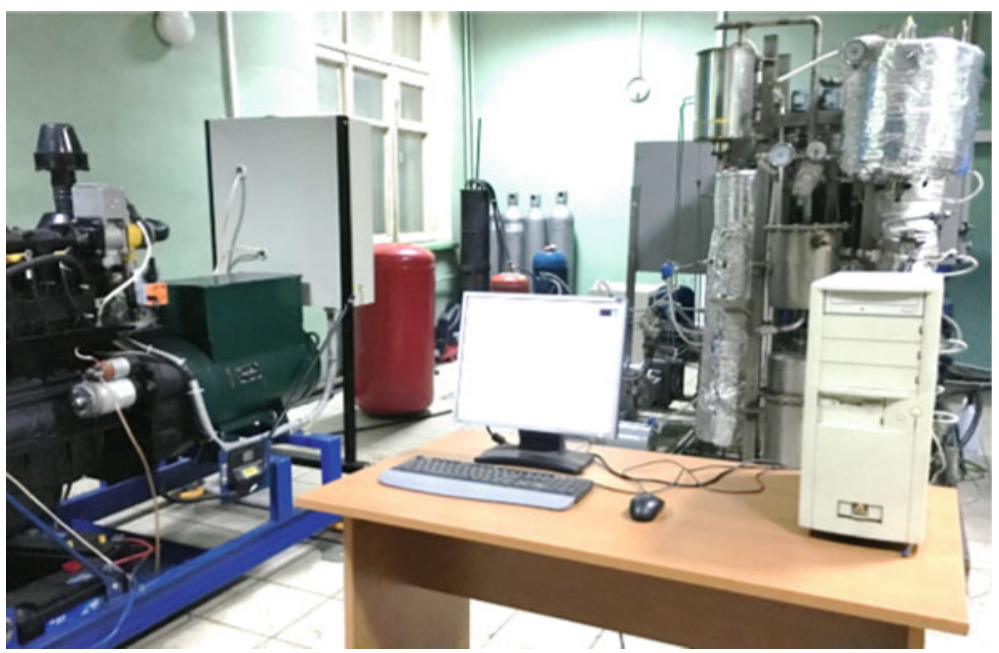

Fig. 2 ISS and HDTB during test

Table 1 Parameters monitored during test

\begin{tabular}{l|l|l}
\hline Parameter & $\begin{array}{l}\text { Unit of } \\
\text { measurement }\end{array}$ & Value \\
\hline Energy consumption in allothermal and autothermal regimes & $\mathrm{kW}$ & $16.5 / 7.8$ \\
\hline Gas fuel consumption of HDTB in allothermal/autothermal regime & $\mathrm{nm}^{3} / \mathrm{h}$ & $12 / 8.1$ \\
\hline Gas fuel pressure before gas pressure and flow sensor input & $\mathrm{atm}$ & $\begin{array}{l}1.95- \\
2.2\end{array}$ \\
\hline Operating pressure in SCHD reactor & $\mathrm{MPa}$ & $23-27$ \\
\hline $\begin{array}{l}\text { The amount of organic fuel fed to the reactor (for each portion: } \\
\text { emulsion, suspension, solution) }\end{array}$ & 1 & 2.8 \\
\hline
\end{tabular}

test bed by a high-pressure proportioning pump in a periodic mode $(100 \mathrm{ml}$ per one in-feed). SCHD reaction has been carried out in allothermal as well as autothermal regime within $60 \mathrm{~s}$, while $100 \mathrm{ml}$ of $50 \%$ (by mass) hydrogen peroxide solution has been fed in autothermal regime in parallel. During HDTB independent starting and operation in various modes, the value monitoring of several parameters such as LHG consumption by GPPP; energy input; discharge of water-organic mixtures (Table 1) stipulated by the program and testing methods have been carried out, and the parameters have been fixed with high-pressure pump running.

The gas-vapor mixture produced in the course of SCHD reaction has been separated into fluid and gas phases in a heat exchanger. Gas phase has been accumulated in a gasometer included in HDTB, whereupon the samples have been taken to study the phase. 


\section{Results and Discussion}

Since high calorific gas may be a reaction product of hydrothermal pyrolysis of aqueous mixtures of organic waste and fuels, then gases sampled in allothermal regime of HDTB autonomous operation could be used to determine gas composition as well as to evaluate its usability as a fuel for GPPP.

Initially, the experimental verification of the produced gas combustibility has been carried out by means of the Bunsen burner (Figure 3).

Then, to analyze the combustible gas, samples have been taken into gas pipette of gas sampling and storing instrument. The samples composition analysis of the gas produced in the course of hydrothermal destruction of fuel and waste samples has been carried out by chromatographic method in a laboratory of the Common Use Centre at D. I. Mendeleev University of Chemical technology of Russia. The results of the sample analysis have shown that the produced gas may have the compositional resemblance to synthesis gas and net calorific value (Table 2) calculated by the computational method (State Standard 22667-82) with the following formula:

$$
Q=\sum_{i=1}^{n} Q_{i} \cdot C_{i}
$$

where $\mathrm{Q}_{i}$ is gas combustion heat of the ith component in gas and $\mathrm{C}_{i}$ is proportion of the ith component in gas.

Fig. 3 The experimental verification of SCHD reaction product

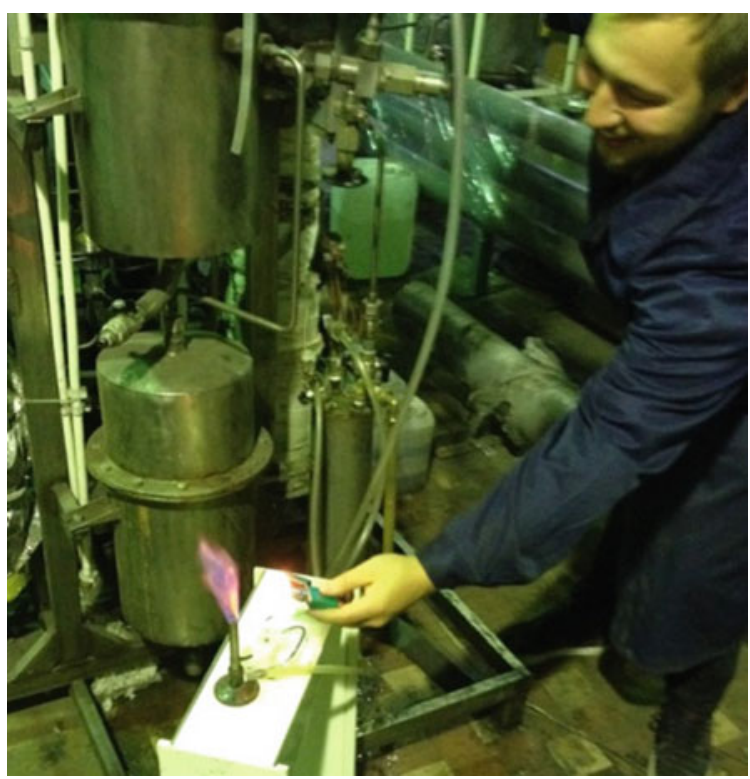


Table 2 The results of gas sample analysis produced during tests on HDTB independent starting

\begin{tabular}{l|l|l|l|l|l|l|l|l|l|l}
\hline No & $\begin{array}{l}\text { Combustible } \\
\text { gas (CG) }\end{array}$ & \multicolumn{6}{|l|}{ Concentration of the components } & \multicolumn{2}{l|}{$\begin{array}{l}\mathrm{Q}_{\text {net }} \\
\left(\mathrm{MJ} / \mathrm{m}^{3}\right.\end{array}$} \\
\cline { 2 - 10 } & $\mathrm{CO}$ & $\mathrm{CO}_{2}$ & $\mathrm{H}_{2}$ & $\mathrm{CH}_{4}$ & $\mathrm{C}_{2} \mathrm{H}_{6}$ & $\mathrm{C}_{2} \mathrm{H}_{4}$ & $\mathrm{C}_{3} \mathrm{H}_{8}$ & $\mathrm{C}_{3} \mathrm{H}_{6}$ & \\
\hline 1 & $\begin{array}{l}\text { Synthesis gas } \\
\text { for a } \\
\text { comparison) }\end{array}$ & $\begin{array}{l}15- \\
18\end{array}$ & $\begin{array}{l}30- \\
32\end{array}$ & $\begin{array}{l}38- \\
40\end{array}$ & $9-11$ & - & - & - & - & $11-12$ \\
\hline 2 & $\begin{array}{l}\text { CG (during } \\
\text { whey } \\
\text { destruction) }\end{array}$ & 0.17 & 22.33 & 34.92 & 14.33 & 2.24 & 0.87 & 0.28 & 0.73 & 11.11 \\
\hline 3 & $\begin{array}{l}\text { CG (during } \\
\text { rape oil } \\
\text { destruction) }\end{array}$ & 2.87 & 25.96 & 19.6 & 14.27 & 9.52 & 10.86 & - & - & 20.08 \\
\hline 4 & $\begin{array}{l}\text { CG (during } \\
\text { crushed } \\
\text { buckwheat } \\
\text { hull } \\
\text { destruction) }\end{array}$ & 1.57 & 20.11 & 23.84 & 19.63 & 9.48 & 8.57 & 1.61 & 4.29 & 22.39 \\
\hline
\end{tabular}

The results of gas samples analysis and net calorific value may bear witness to the possibility of using the combustible gas as a fuel for GPPP.

Thus, plans have been made to develop the obtained results at the next stage of the applied research and the experimental research. The work on optimization of the heat energy efficiency of independent starting and autonomous operation of the test bed would be done while conducting an experimental research on modernized HDTB. To achieve this, equipping ISS with the process equipment preparing the combustible gas to be used as a fuel for GPPP as well as selecting efficient parameters of SCHD reaction and methods of the reaction product quality improvement have been planned.

\section{Conclusion}

The independent starting system of HDTB which may be considered as a basic block of AES based on supercritical hydrothermal destruction of organic waste and fuels to produce electric energy has been developed and tested. The experimental research has verified the possibility of independent starting and autonomous operation of the test bed for various types of aqueous mixtures. The qualitative and quantitative composition of the combustible gas produced during HDTB test may provide the possibility to use it as a fuel for GPPP. The test has verified the efficiency of AES blocks (process equipment for preparing aqueous mixtures, independent starting system, and hydrothermal destruction test bed). The promising directions for follow-up studies and its realization have been identified. 
Acknowledgement The study has been financially supported by The Ministry of Education and Science of the Russian Federation, Grant Agreement No. 14.607.21.0126 dated October 27, 2015. Unique identifier: RFMEFI60715X0126.

\section{References}

1. Popel, O.S.: Renewable energy sources in present and state-of-the-art energy. Russ. Chem. J. 52(6), 96-106 (2008) (in Russ.)

2. Mazalov, Y., Pustovgar, A., Grigorev, V., Vedenin, A., Adamtsevich, A.: Technology for hydrothermal destruction of organic fuel materials. Appl. Mech. Mater. 752, 873-877 (2015).

3. Yakaboylu, O., Harinck, J., Smit, K.G., de Jong, W.: Supercritical water gasification of biomass: a literature and technology overview. Energies. 8(2), 859-894 (2015)

4. Efimov, N.N., Fedorova, N.V., Mirgorodskiy, A.I., Kolomiytseva, A.M.: Gasification of Organic Waste and Fuels. Advantages Present Nat. Sci. 1, 15-21 (in Russ.) (2007)

5. Psarov, S.A.: Thermal effects of organic matters oxidation in supercritical water. Author's abstract of master's dissertation, p. 24. Novosibirsk (in Russ.) (2006)

6. Fediayeva, O.N.: Transformations of Low Grade Fuels in Supercritical, p. 256. Ph.D. dissertation, Novosibirsk (in Russ.) (2014)

7. Astakhova, L.V., Grigoryev, V.S., Mazalov, Yu.A., Nizovtsev, V.E.: High-toxic substances disposal. Prod. Ecol. 8, 66-70 (in Russ.) (2011)

8. Mazalov, Yu.A., Bersh, A.V., Merenov, A.V. and others.: Production of heat and electric energy by organic waste combustion in aqueous media. Energy Saving and Energy Supply in Agriculture. Proceedings of the 6th International Scientific Conference on Applied Sciences and Engineering (2008). Part 1. Problems of Energy Supply and Energy Saving. 390-395, (in Russ.)

9. Mazalov, Yu.A., Svitsov, A.A.: The use of SCWO for recycling organic waste. Water Mag. 1 (77), 36-38, (in Russ.) (2014)

10. State Standard 5542-2014.: Natural combustible gases for commercial and domestic use. Specification. Standartinform, Moscow (2014), (in Russ.)

Open Access This chapter is licensed under the terms of the Creative Commons Attribution 4.0 International License (http://creativecommons.org/licenses/by/4.0/), which permits use, sharing, adaptation, distribution and reproduction in any medium or format, as long as you give appropriate credit to the original author(s) and the source, provide a link to the Creative Commons license and indicate if changes were made.

The images or other third party material in this chapter are included in the chapter's Creative Commons license, unless indicated otherwise in a credit line to the material. If material is not included in the chapter's Creative Commons license and your intended use is not permitted by statutory regulation or exceeds the permitted use, you will need to obtain permission directly from the copyright holder.

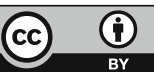

